\title{
Larotrectinib in a NTRK-rearranged soft tissue sarcoma in the neoadjuvant setting: a case report.
}

Catherine Percy ${ }^{1}$, Schubert Thomas ${ }^{1}$, Christine Galant ${ }^{1}$, Thomas Kirchgesner ${ }^{1}$, and Filomena Mazzeo ${ }^{1}$

${ }^{1}$ Cliniques universitaires Saint-Luc

October 13, 2020

\begin{abstract}
NTRK gene-fusions are rare but can occur in diverse cancers. The NTRK inhibitor larotrectinib is newly approved by the FDA. This paper reports the first case of a man with a NTRK-rearranged soft tissue sarcoma treated with larotrectinib in the neoadjuvant setting, in Belgium, to avoid limb amputation.
\end{abstract}

\section{Hosted file}

Case report Catherine_soumission.pdf available at https://authorea.com/users/366713/articles/ 486389-larotrectinib-in-a-ntrk-rearranged-soft-tissue-sarcoma-in-the-neoadjuvantsetting-a-case-report
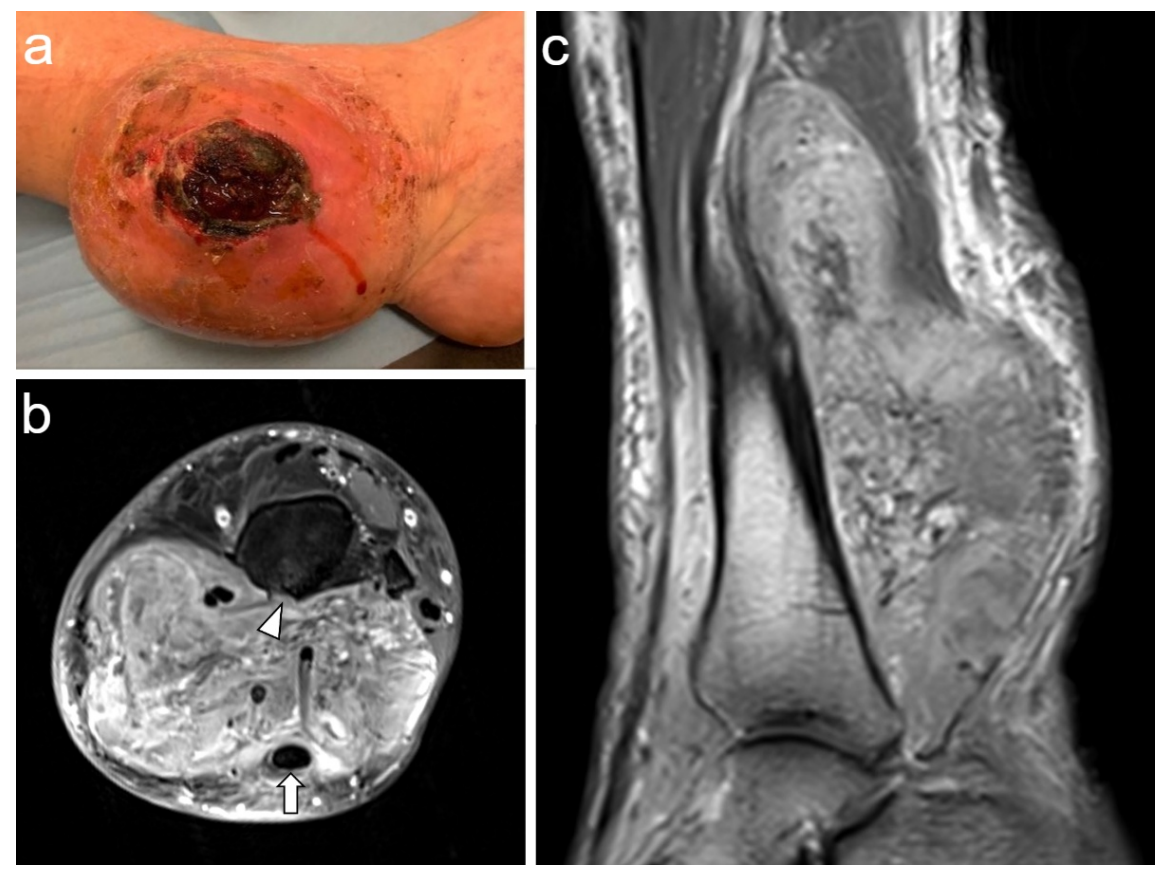

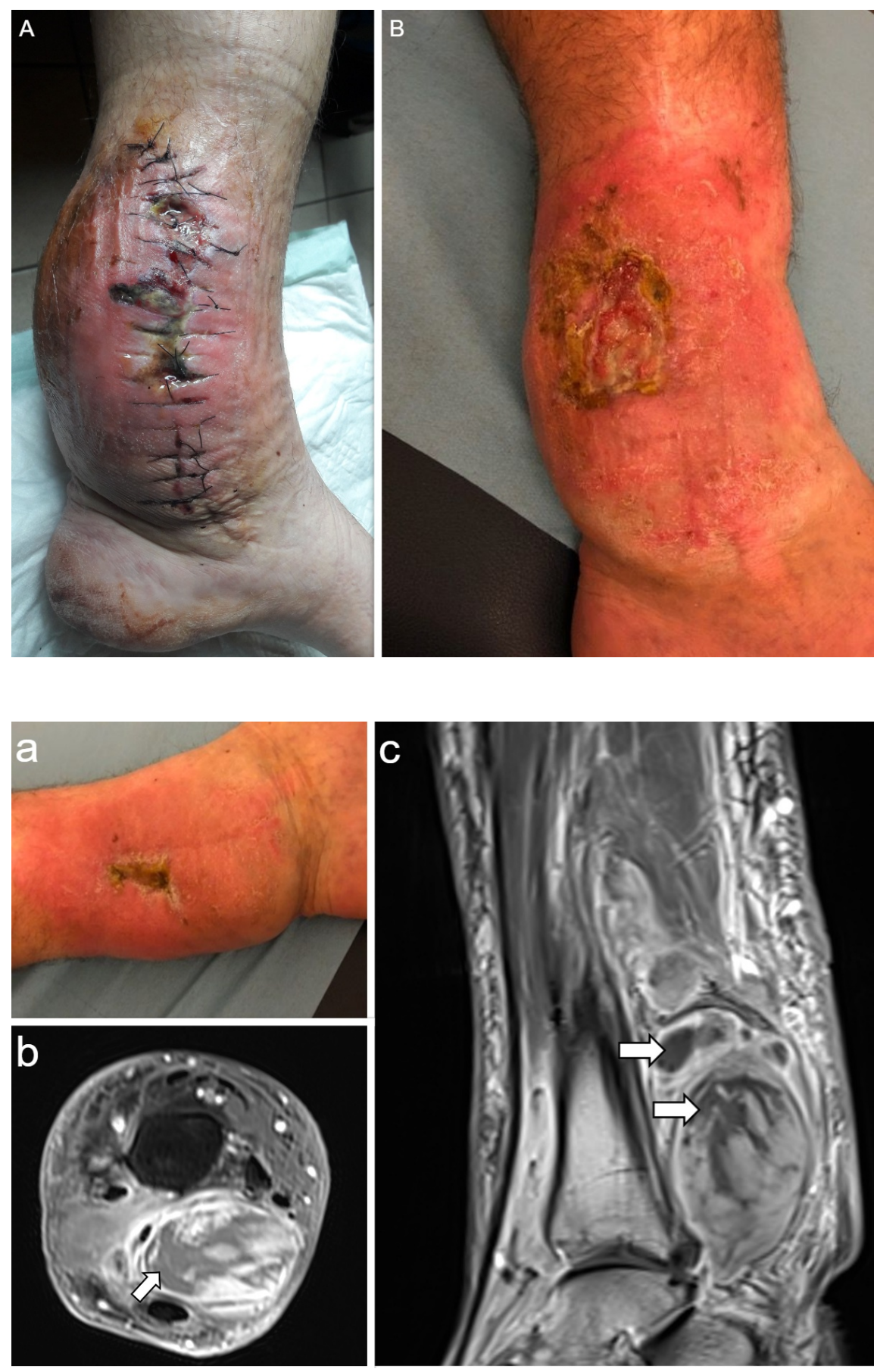